\title{
Memorias y justicia a través del océano. Argentina y España frente a sus últimas dictaduras
}

\author{
Manuel Sánchez-Moreno \\ Universidad de Córdoba
}

\begin{abstract}
Resumen:
El artículo propone una revisión de las relaciones formales e informales, institucionales y migratorias entre Argentina y España durante las Juntas Militares y el Franquismo, respectivamente, así como sus procesos de justicia transicional. Las migraciones cíclicas entre ambos países motivadas por cuestiones políticas y económicas han hecho que desde el siglo XIX existiese un interés mutuo que ha unificado unos marcos de pensamiento y cultura común en torno a la memoria comparada.
\end{abstract}

Palabras clave: memoria histórica, justicia transicional, Argentina, España, género, derechos humanos

\begin{abstract}
:
The article proposes a revision of the formal and informal, institutional and migratory relations between Argentina and Spain during the Military Boards and the Franco regime, respectively, as well as their transitional justice processes. Cyclical migrations between the two countries base on political and economic issues have meant that since the nineteenth century there was a mutual interest that has unified some frameworks of thought and common culture around comparative memory.
\end{abstract}

Keywords: historical memory, transitional justice, Argentina, Spain, gender, human rights

A menudo circunscribimos la memoria a un elemento de identidad nacional, enlazado con una cultura, etnia, territorio o cosmovisiones propias. Es como si la memoria se ciñese a unas fronteras que tradicionalmente se han asociado a los Estados-nación y a sus divisiones internas en forma de provincias o de minorías nacionales. Sin embargo, esta configuración de la memoria peca de un enfoque colonial y simplista al no considerar la movilidad humana como factor fundamental que rompe las fronteras.

Ambas cuestiones, colonialidad y migraciones están presentes en la historia, pero sobre todo en la memoria compartida de Argentina y España. Como se podría aplicar con cualquier colonia, las relaciones con la metrópolis se pueden articular entorno a los estudios de memoria en una serie de momentos: la época precolonial, la época colonial, la independencia, y las nuevas relaciones entre países independientes. Nosotros nos centraremos en este último y concretamente en la memoria traumática vinculada a las últimas dictaduras, cuando a menudo la migración se transforma en exilio: 
toda la historia cultural de la hispanidad es una serie continuada de censuras, supresiones y desplazamientos (fundamentalmente de la voz de los exiliados, de la historia no oficial), ocultos detrás de una mítica identidad carente de fisuras que, desde la engañosa exaltación de los "héroes" de la Conquista, ha englobado bajo la confusa y ambigua palabra "civilización", una herencia (la lengua y la religión) tan útil como destructiva en su intento de homogeneización. (Aznar y Wechsler 16)

Estamos ante un juego de memorias en un régimen binario que fue colonizado para no recuperar su estatus original y siguió en un régimen migratorio que tergiversó aún más la madeja. Lo binario se caracteriza por la confrontación de dos formas opuestas y desconectadas que conservan un sistema de valores y características propias. Este distanciamiento binario de las memorias pertenecientes a dos espacios diferenciados se basa en la memoria colectiva.

\section{Marco teórico}

Halbwachs hace una primera distinción entre memoria individual y memoria colectiva. Asegura que son las personas las que recuerdan porque pertenecen a un grupo social, se ubican en un tiempo y espacio concretos. La memoria colectiva está fragmentada en sí misma por varios sesgos, uno de ellos es la intervención de una memoria oficial sostenida por el Estado que se puede imponer de manera más o menos violenta y por lo tanto reprimir las memorias colectivas. Otros sesgos pueden ser la etnia, el género o la diversidad afectivo-sexual.

En cualquier caso, la memoria colectiva, pese al discurso oficial y las transversales como el de género, se sostiene "mientras la adscripción al grupo pertenece" (Aguilar 38). Pero si no se han podido constituir grupos, si las memorias no se han podido expresar o han permanecido recluidas en el ámbito de lo privado, estamos ante memorias autobiográficas que han tendido a "desteñirse con el tiempo, a menos que sea periódicamente reforzada a través del contacto con personas con quienes se comparten las experiencias del pasado" (Coser 24). En definitiva, recordar "es reforzar el vínculo social, por el que el olvido se explica como escisión del grupo de referencia. Mientras se mantiene el contacto con un grupo y la identificación con él [...] el pasado de cada uno tiene referentes comunes que perviven por la manera de continuidad del grupo" (Aguilar 42).

La pluralidad de memorias colectivas como pluralidad de grupos de referencia, implica que el problema de la memoria es también un problema de poder social (Hutton 69). En este sentido hay unos usos intencionados del pasado, cuyo objetivo es marcar una identidad social que se define por exclusión de los tipos sociales alternos, es decir de la 'otredad'. Un binarismo marcado por la separación — y abismo- entre lo público y lo privado, que no tiene derecho a pasar a la historia oficial y en el que se encuentran subsumidas las memorias de las personas empobrecidas, vencidas, las mujeres, las excluidas, la sexualidad no normativa... Se crea una memoria oficial excluyente que fija los acontecimientos en la historia (Olick y Robbins 126-127).

La emergencia de las nuevas corrientes excluidas de la memoria oficial da cabida a una diversidad antes silenciada. Emergen memorias antes dominadas reivindicando 
para sí un pasado ocupado o colonizado por voces que no eran las suyas. Los feminismos y otras reivindicaciones sociales se basan en un principio ético-discursivo común: "el derecho fundamental de los grupos humanos no-representados o desfigurados a hablar y representarse en dominios definidos política e intelectualmente de los que suele excluírseles, usurpando sus funciones significadoras y representativas y anulando su realidad histórica" (Said 215). El derecho a narrar entendido como la propagación de ideas e ideales, permite mostrar sin censuras la vida que llevamos, aquello que somos, el momento donde estamos, de dónde venimos y cuestionar las costumbres que heredamos y los conflictos circundantes (Bhabha 180). En definitiva, el derecho a la memoria de las personas a las que se les negó esta posibilidad. También el derecho a la memoria se torna deber de memoria, como constancia de lo recordado a las personas que vienen después (Castilla del Pino 16), usando las experiencias como fuente resiliente de construcción del futuro. Esto se asienta en la fuerte relación entre memoria e identidad: "la memoria es la condición necesaria para el logro de nuestra identidad [...]. Somos, pues, porque tenemos memoria; es más, somos nuestra memoria." (Castilla del Pino 19)

Esta memoria como lucha por el reconocimiento de una identidad y experiencias ha sido planteada por Foucault en varias ocasiones. Una primera aproximación la hace con el concepto de 'saberes subyugados', aquellos ocultos en el conocimiento histórico y aquellos "que han sido descalificados como inadecuados para su tarea o insuficientemente elaborados: saberes ingenuos, ubicados bastante abajo en la jerarquía, por debajo del nivel requerido de conocimiento o cientificidad." (Foucault, Power/Knowledge 82) Es decir aquellos conocimientos realizados por voces no autorizadas. Este tipo de saberes no reconocidos son cruciales para comprender el pasado. En este sentido habla de la memoria como fuerza política: "en tanto la memoria es verdaderamente un factor muy importante en la lucha (en realidad, las luchas se desarrollan de hecho en una suerte de movimiento consciente de la historia hacia delante), si se controla la memoria de la gente, se controla su dinamismo" (Foucault, "Film" 123-124).

Conceptualizando lo anterior, Foucault introduce el término 'contra-memoria' para aludir a aquellas 'historias' que revisan la historia oficial mediante el suministro de nuevas perspectivas sobre el pasado (Foucault, Language 160). Actúan como una resistencia y desunión respecto a la continuidad histórica mediante la heterogeneidad y la discontinuidad (Foucault, Society 69-70). En la primera lo que se ve como leyes, derechos u obligaciones desde el punto de vista del poder, es un abuso de poder, violencia e imposición. En la segunda, el poder actúa dividiendo el cuerpo social entre lo iluminado y lo que permanece en la sombra de manera petrificada para que exista un orden.

Esta tensión frente a las versiones oficiales de la continuidad histórica puede estar ligada a una represión sostenida en el tiempo y a acontecimientos traumáticos de la historia que, para LaCapra, preparan su regreso atrasado como discurso de la memoria (Klein 140). En este lugar ubicamos los movimientos sociales que, desde la justicia histórica y los derechos humanos, reivindican las experiencias, identidades y memorias mutiladas desde el último tercio del siglo XX.

Estos movimientos no sólo traen la contramemoria, como contrapoder, sino que son portadores de una postmemoria. Es decir, no es necesario que hayan vivido los hechos para traerlos al presente y reivindicarlos. Las personas portadoras de esta postmemoria pueden ser familiares que han recibido una tradición oral o movimientos sociales que, al ser herederos de una identidad, reelaboran una memoria colectiva antaño 
fragmentada - y silenciada - para "contrarrestar la tendencia de la historia a oficializar un cierto estado de la memoria, una memoria ideológica" (Lavabre 40). El concepto de postmemoria, de gran importancia para las reivindicaciones políticas y jurídicas, se debe a Marianne Hirsch, que define así una conexión mediata con el pasado, generalmente traumático (Hirsch 22), trasformado ahora en postraumático (LaCapra 149), al transmitir una victimización.

Esta memoria y postmemoria colectiva propia de un territorio, en confrontación con otro del que antaño formó parte, se convierte en diálogo en torno a tres cuestiones fundamentales: la movilidad humana, las relaciones gubernamentales y la reivindicación de la memoria que en el caso concreto de España y Argentina se recorre en cuatro momentos: 1. Los procesos migratorios de España a Argentina a finales del siglo XIX y principios del XX para ocupar nuevas tierras. 2. El exilio republicano español durante la Guerra Civil y la postguerra franquista. 3. El exilio argentino a España durante la dictadura de las Juntas Militares. Y 4. La migración argentina a España durante la crisis económica del corralito.

Dos memorias, dos identidades nacionales que son antónimas en su régimen binario, pero que, como algunos antónimos, son sinónimos en su raíz. La distancia entre lo antónimo y lo sinónimo, lo tonal y lo atonal, la memoria y el olvido, lo conocido y lo siniestro es un espacio abismal de intercambios que lejos de estar en confrontación, se dejan al desordenado juego de los diálogos y las afinidades electivas. Algo que sólo es posible desde la diferencia.

Podríamos llamar a esto los 'antónimos dialécticos'. Se ejemplifica muy bien en el concepto de 'Madre Patria'. Bajo un enfoque de género, la patria, la identidad nacional, es del patriarcado, quien posee la tierra. Pero necesita la 'excelencia' reproductiva de la madre aunando en un término los estereotipos masculinos y femeninos, como residuo cultural y amable de la colonización. Del mismo modo, el olvido y la memoria entran en este juego de antónimos dialécticos. El primero responde a una razón amnética, la segunda a una razón anamnética. Y de esta nace una justicia anamnética que se encarga de la reparación a las víctimas contra la amnistía y la impunidad (Metz 77).

Ambas configuran lo que representan en torno a las ausencias, las presencias y las intermitencias de su discurso, aquello que aparece y desaparece para volver a aparecer como trauma o reivindicación política, estética y jurídica del pasado. Dicho de otra manera, si la memoria almacena, codifica y recupera; el olvido disipa, destruye y pierde. De este modo, en el abismo que va de una al otro en el juego de los antónimos dialécticos se responde a qué se almacena o disipa, cómo se codifica o destruye y cuándo se recupera o se pierde.

\section{Memoria política}

La memoria política contiene las relaciones diplomáticas y formales entre Argentina y España. Es decir, aquello que merece la pena ser registrado y archivado en la memoria y en la historia. Se podría decir que a un nivel macro constituye la historia de los vencedores y la necesidad de que existan vencidos sin capacidad de réplica. Los vencidos adquieren una entidad de subcultura o cultura accesoria sin dimensión política, es decir sin voz ni participación plena. Son sólo imagen, ilustración que justifica la victoria de los vencedores sobre cuya barbarie se asienta un presente amnético. 


\section{La Guerra Civil Española}

Las relaciones institucionales entre España y Argentina desde la Guerra Civil y en la postguerra estuvieron marcadas por una solidaridad bajo dos formas de ideología: el apoyo antifascista a la II República ante el golpe de Estado franquista y el apoyo anticomunista a la dictadura de Franco.

Durante la II República española, la polarización de la migración española frente al nuevo sistema de gobierno también estaba presente en el país rioplatense. Del lado franquista encontramos sociedad civil organizada en torno al Club Español de la calle Bernardo de Irigoyen de Buenos Aires, el Centro de Acción Española o la Agrupación Monárquica Española (Quijada 107-108). Del otro lado, encontramos múltiples Centros Republicanos y los centros regionales de inmigrantes como el gallego o el asturiano, que constituían sectores populares e intelectuales opuestos al fascismo. Junto con todas estas instituciones también apoyarían los Centros Socialistas y se crea ad hoc el grupo Amigos de la República, luego llamado Solidaridad y confraternidad española (Bins 34).

Cuando se produjo el golpe de estado militar en 1936 que puso en jaque al gobierno republicano en España, el presidente de Argentina era el conservador Agustín Pedro Justo (1932-1938). Justo mantuvo una postura ambigua y en consonancia con la política internacional de no intervenir en la contienda española, reflejándose en el propio gobierno posturas simpatizantes con la república y otras de tendencia fascista (Muchnik 170). Por su lado, los golpistas españoles liderados ya por Franco e intentando reorganizarse como gobierno en plena contienda, intentaron abrir puentes diplomáticos con Argentina, sin que fuesen apoyados de manera oficial, aunque sí oficiosa por parte de determinados sectores del gobierno y la sociedad argentina, especialmente la oligarquía agraria e industrial perteneciente a la Sociedad Rural Argentina (Quijada 31).

En plena contienda, el apoyo tácito al golpe se concretó en el derecho al asilo, sirviendo la Embajada de Argentina en Madrid como refugio de simpatizantes golpistas, que no cedió a entregar a las autoridades republicanas a muchas personas refugiadas entre sus muros (Quijada 39-47). Entre agosto de 1936 y mayo de 1937, el torpedero Tucumán y el crucero 25 de Mayo evacuaron a 1526 personas, de las que 553 eran argentinas, 651 españolas y el resto de otras nacionalidades (Figallo 133). El caso contrario, lo tenemos en el buque español Cabo San Antonio que arribó en el puerto de Buenos Aires el 28 de octubre de 1936, llevando a personas afines a la república que fueron detenidas, juzgadas y deportadas (Quijada 47-52).

Esto se debió al fuerte sentimiento anticomunista que se vivía en Argentina, existiendo una ley de represión de actividades comunistas desde 1936 (Carnaqui), y a la ficción que había hecho creer el franquismo de librar una batalla contra el marxismo y los 'rojos' estereotipados en la forma de gobierno republicana. A esto hay que sumar el apoyo del ejército argentino y la Iglesia católica al golpe de Estado, viendo en Franco al mejor representante del estado confesional y nacionalcatólico propuesto como antítesis del modelo laico republicano (Trifone y Svarzman 59). A Justo le sucedería entre 1938 y 1940 el presidente Roberto Marcelino Ortiz que siguió la misma línea.

El fin de la guerra con el triunfo de los militares golpistas y la instauración del franquismo, supuso un importante exilio republicano hacia Argentina. Desde 1880, el 
país rioplatense había recibido a millones de inmigrantes europeos para poblar su extenso territorio hasta que cerró sus puertas en 1930 (Sánchez Alonso; Yáñez). En 1936, con el inicio de la guerra, los inmigrantes republicanos —exiliados- serían asociados al comunismo en un momento de fuerte repulsión hacia esta tendencia política. Políticamente, el gobierno argentino hacía una distinción entre migración y refugio político, que veían como algo nocivo (Senkman).

Desde el inicio de la guerra y especialmente desde 1938 se trabó el acceso al país desde los consulados de Argentina, rechazando solicitudes de ingreso (Schwarzstein, "La llegada"). Con la derrota republicana en 1939 hubo un exilio masivo a diversos destinos de Latinoamérica, algo que continuó durante el periodo de postguerra (Schwarzstein, Franco y Perón 94).

\section{Perón y el franquismo}

Establecido el régimen dictatorial y en plena miseria de postguerra, España se encontraba aislada internacionalmente (Payne 155-167). La ONU condenó al franquismo e impidió entrar a España en la organización en 1946, retirando a sus embajadores. Mediante la Resolución 39(I), la recién creada ONU reconoce que "en origen, naturaleza, estructura y conducta general, el régimen de Franco es un régimen de carácter fascista, establecido en gran parte gracias a la ayuda recibida de la Alemania nazi de Hitler y de la Italia fascista de Mussolini."

Ese mismo año, el militar Juan Domingo Perón iniciaba el primero de sus dos gobiernos consecutivos en Argentina (1946-1952 y 1952-1955). Perón establecerá una serie de relaciones con Franco basadas en una afinidad ideológica: la 'tercera posición' entre el capitalismo y el comunismo, la cultura e historia compartida de la hispanidad, la oposición a la intelectualidad y partidos políticos, así como el apoyo de la derecha, y cuestiones económicas, donde se enmarcan los acuerdos comerciales y migratorios (Rein 27). Por su lado, el peronismo generó un gran rechazo entre las españolas y españoles exiliados en Argentina, ya que percibían su gobierno como una dictadura de origen militar y con simpatías hacia el franquismo y el fascismo (Schwarzstein, Franco y Perón 173).

La hispanidad se torna como una efectiva diplomacia blanda de corte cultural. Esto enlazaba con el propio nacionalcatolicismo que, en la península y los territorios de ultramar emanaba de Castilla, Isabel la Católica y la eliminación del pluralismo religioso, algo teorizado por Ramiro de Maeztu en su obra de 1934, Defensa de la Hispanidad. En su obra se concibe la colonización como un proceso solidario, católico y civilizatorio alejado de la idea de dominio. No era explotación sino expansión cultural para crear una gran unidad familiar. En este sentido la conquista de América y la expulsión de judíos y musulmanes de España se torna como el eje fundamental histórico del que parte el régimen franquista y sus relaciones con la América hispana (Di Febo 77; Pecharromán 82-83).

En este contexto se establecen en 1946 los primeros acuerdos sobre inmigración entre Franco y Perón. Argentina volvía a abrir las puertas a la inmigración española, pero intentando eliminar la entrada de exiliados de izquierda. Algo sólo posible si podían rastrear su pasado, estaban estigmatizados como 'rojos' por el régimen franquista 
o si la corrupción de los agentes de aduanas permitía la entrada al país (Devoto 404405). Según Palazón (303), en el periodo que va de 1946 a 1958 Argentina se convertiría en el principal receptor de inmigración española.

Este nuevo restablecimiento migratorio, concretamente entre ambos países gozaba de un marco normativo e institucional denso. En 1946 se firma el Convenio Comercial y de Pagos, donde se aseguraba el buen trato por parte de las autoridades argentinas a las personas migrantes españolas que se comprometían no poner trabas y la exportación de productos que aliviaran en parte el hambre en España. Se crea la Delegación Argentina de Inmigración en Europa (DAIE) y la Comisión de Recepción y Encauzamiento de Inmigrantes (CREI) (República Argentina 703-729). Todas estas condiciones se mejorarían en el protocolo Franco-Perón de 1948 (Memoria del Ministerio de Relaciones Exteriores y Culto 895-898). Por su lado, España restablecía la Ley de Emigración de 1924 regulada por el Instituto Español de Emigración dentro del Ministerio de Trabajo. En 1948 se ratificaría el Convenio de Emigración entre España y Argentina que regularía los tipos de emigración y mostraría internacionalmente que España no estaba sola (Calvo et al.).

En este contexto se produce la visita a España de la esposa de Perón, Eva María Duarte 'Evita', dentro de una gira por Europa. La primera dama argentina se convertirá en el icono de la hispanidad. Aunque su imagen en España no será publicitada como en Argentina. Si en su país natal era la luchadora política de los descamisados obreros, aquí se presenta como una elegante dama embajadora de Perón, una imagen de feminidad más acorde con la del franquismo (Pelta 182). Este ideal estaba asociado a la tradición católica y a un discurso de la 'excelencia' de la mujer respecto al varón. Es decir, la excelencia moral de las mujeres se origina en aquellos espacios que realmente la subordinan: lo doméstico, la maternidad, la defensa y transmisión de la tradición (Cobo 251). Se podría decir que ellas son la 'madre patria' una "heterodesignación patriarcal" (Amorós 175).

Tras este momento, y motivado por una serie de incumplimientos en los acuerdos comerciales, la crisis económica e inflación argentina y el cambio de foco español hacia EEUU se produciría un enfriamiento en las relaciones con Perón, que ya en 1954 cambiaría el concepto de hispanidad por el de latinidad (Delgado 177).

En todas estas idas y venidas, se configuró una memoria española en Argentina diferenciada por una identidad nacional y a la vez transida por la clase, el género, la ideología política, etc. (Alted 391; Schwarzstein, Franco y Perón 199). Unas nuevas identidades españolas que se constituyen en nuevas comunidades diferenciadas dentro de Argentina, esta vez marcadas por la guerra y por el exilio que no compartían con las comunidades españolas que se establecieron en torno al cambio del siglo XIX al XX. La distancia y la cercanía respecto a sus paisanas y paisanos y otras comunidades, así como la memoria y el olvido respecto a sus raíces en España marcarán las generaciones posteriores en un fuerte antifranquismo (Schwarzstein, Franco y Perón 200).

\section{De la última dictadura argentina a la transición española}

Tras el derrocamiento de Perón, Argentina sería una sucesión de gobiernos democráticos y golpes de Estado militares, y España seguiría en la inmutabilidad franquista. En 
1969, bajo la dictadura del comandante Onganía (1966-1970) se suscribiría un convenio de doble nacionalidad entre ambos países que rige hasta la fecha (Lozano).

Este periodo argentino, una sucesión de militares al frente del gobierno se llamaría 'Revolución Argentina' y finalizaría en 1973 con la vuelta del peronismo y de la figura de Juan Domingo Perón. El presidente ya viudo, estaría en un largo exilio que le llevó a Paraguay, Nicaragua, Panamá (donde conoció a María Estela Martínez 'Isabelita'), Venezuela, República Dominicana y finalmente España donde se estableció en 1960 casándose con Isabelita y manteniendo una relación meramente formal con Franco hasta que en 1973 partiera de nuevo hacia una Argentina más amigable gracias al movimiento del neoperonismo (Algañaraz).

Argentina se preparaba para elegir por tercera vez al militar como presidente de la nación que, al morir en 1974 sería sustituido por su esposa y vicepresidenta Martínez de Perón. La inestabilidad política de la década de los 1970 hace que se formen grupos armados como el Ejército Revolucionario del Pueblo (ERP) y Montoneros y grupos parapoliciales como la 'Triple A' (Alianza Anticomunista Argentina), que se manifiestan en contra de las medidas del gobierno de Martínez de Perón y de las acciones represivas de las Fuerzas Armadas en el comienzo del terrorismo de Estado (Tapia).

Ya en septiembre de 1974 los detenidos políticos eran considerados 'delincuentes terroristas', sancionándose la ley 20.840 de Seguridad Nacional, que prescribía penas para quien atentase contra el "orden económico, político y social de la Nación, por vías no establecidas en la legislación vigente", privilegiando el arresto sobre una sentencia e incrementando las personas en prisión. En 1975 vendrían los "decretos de aniquilamiento" que permiten actuar a las Fuerzas Armadas, estableciéndose los primeros centros clandestinos de detención (Slatman 465). Sería el comienzo de la lucha contra la denominada 'subversión'.

De este modo, antes del golpe de Estado militar que se estaba preparando, ya estaban los cimientos legales e instrumentales de la represión, basada en la lucha contra posturas cercanas al comunismo en un momento de fuerte polarización mundial. Contando con la complicidad de países como España, Francia y Estados Unidos, el nuevo gobierno peronista, que siempre había sido anticomunista encuentra su apoyo en el ejército (Robin). La Iglesia Católica supuso el sustento espiritual y psicológico para las acciones militares (Verbitsky 373). El arzobispo de Tucumán, Aramburu, llegó a ensalzar en 1975 a Franco durante el funeral que se ofreció en la catedral de Buenos Aires, alabando su catolicismo y el modelo que representaba para los militares argentinos (Clarín, "Funeral").

El golpe se autodenominó 'Proceso de Reorganización Nacional' (1976-1983) comandado por cuatro Juntas Militares sucesivas conformadas por los tres ejércitos y cuyo primer presidente fue Videla. La jerarquía católica estuvo en su toma de posesión (Obregón 58). Y el Vaticano celebró la reputación moral de Videla y la vocación cristiana del nuevo gobierno (Obregón 61-62).

La eliminación de todo pluralismo político, la vinculación e identificación con los valores de la Iglesia Católica y el carácter militar de la dictadura tendía puentes con el franquismo en España, que pervivía en la transición española. Un neofascismo que tomaba como referencia los fascismos históricos generados en el periodo de entreguerras, especialmente el español de la 'Madre Patria' basado en la idea de 'hispanidad'. La última dictadura argentina hay que enmarcarla en el 'Plan Cóndor', una suerte de coordinación regional entre las policías secretas y servicios de inteligencia militar de países 
de la región con el fin de compartir información y técnicas represivas frente a las disidencias que pudieran encontrar, mediante una elaborada tecnología terrorista dominada por el asesinato, la tortura, la violencia sexual, el secuestro de menores, la detención y la desaparición forzada (Nilson).

España, que vivía los estertores de un dictador que murió fusilando y condenando a muerte, colaboró activamente con las cuatro juntas militares. Las relaciones entre la dictadura argentina y una España en transición política son complejas: colaboración económica entre ambos países más allá del conocimiento de violaciones de derechos humanos u ocultación de los archivos de la represión argentina en España, marcaron unas relaciones de conveniencia en las que Argentina necesitaba apoyo político y España expandir sus relaciones en el periodo transicional, en forma de convenios comerciales y económicos, o de colaboraciones técnicas (véanse los artículos de Albin). Así, durante el proceso judicial que el juez Garzón abre en España sobre la dictadura argentina, que veremos seguidamente, se demostró que militares españoles viajaron a Argentina entre 1979 y 1983 para impartir talleres, conociendo la situación represiva (ABC).

El impacto sobre la ciudadanía fue excepcional. La importancia de las personas republicanas exiliadas y sus descendientes en Argentina marcó que muchas de las personas detenidas-desaparecidas y muertas durante la dictadura cívico-militar tuviesen la nacionalidad española por nacimiento o por descendencia. Personas exiliadas de izquierda que siguieron manteniendo esta ideología y fueron considerados elementos "subversivos" por discrepar respecto a los militares golpistas. En 1997, la diputada de Izquierda Unida María Ángeles Maestro Martín hace un pedido al Ministerio de Asuntos Exteriores español para conocer a las personas desaparecidas durante la dictadura argentina entre 1976 y 1983. El resultado es un informe (MAE) que parte de un dictamen de la Comisión Especial de Investigación sobre Desaparición de Súbditos Españoles en Países de América, creada ad hoc en 1983 por el Senado español (Senado), donde se recopilan testimonios y nombres de personas desaparecidas durante procesos dictatoriales latinoamericanos con nacionalidad española.

El informe de 1997 se hace eco de la falta de datos aportados por el gobierno argentino encabezado por Menem y de la actividad diplomática para localizar a varias personas españolas, algunas de las cuales fueron liberadas. La acción diplomática española en Argentina estableció las arbitrarias cifras de 28 personas españolas de nacimiento y 209 con la nacionalidad (Pérez). El Registro Unificado de Víctimas del Terrorismo de Estado (RUVTE) de la Secretaría de Derechos Humanos argentina ofrece datos más recientes de víctimas en su último informe de diciembre de 2015. La ascendencia de las víctimas por nacionalidad, es decir argentinas y argentinos con padres y/o abuelos extranjeros es mayoritariamente española (24,5\%). Entre las víctimas extranjeras, incluyendo aquellas naturalizadas argentinas, es decir con doble nacionalidad se encuentran 61 españolas/es (RUVTE).

La prensa española se hizo eco de la intervención diplomática en la liberación de algunas personas detenidas desaparecidas españolas. Un ejemplo es el del inmigrante vasco Jesús María Cabanas que huyó junto con sus padres de la mísera postguerra de Zarauz, para encontrarse años después una represión y violencia del mismo perfil. Su testimonio habla de un 'holocausto argentino': 
Sin saber por qué, el 8 de octubre de 1976 fui secuestrado en plena calle. Me trasladaron a una cuadra militar. Y allí, maniatado y encapuchado, estuve tres meses. Y puedo contarlo gracias a la intervención del embajador español. Porque éramos cuarenta y sólo diez llegamos a la cárcel. [...] El pabellón once es como una ruleta de la esperanza. Allí nadie sabe nada. Si te toca, te tocó. Una noche cualquiera te sacan, suenan un par de disparos, y se acabó. Horas más tarde viene un helicóptero, recoge los cadáveres, y con un bloque de hormigón atado a los pies, arrojan tu cuerpo al río de la Plata. En la estadística serás un desaparecido más. [...] De Sierra Chica, donde estuve dos años, me 'secuestran' y encapuchado nuevamente me llevan a Bahía Blanca. Mis familiares se enteran y vuelve a intervenir la embajada. Me llevan a la cárcel. Se plantea un recurso de amparo. El juez decreta mi libertad. Pero no se cumple. Me trasladan a la prisión de Rawson, a un calabozo, incomunicado; el embajador se entrevista con el ministro del Interior, y después de treinta días me recoge un helicóptero y me traslada al aeropuerto de Eceiza. Escoltado por soldados se me mete en un avión de Iberia y así, con un pantalón y dos camisas, recupero mi libertad en España. (El País)

Por su lado, en el marco de la querella argentina sobre crímenes del franquismo que veremos más adelante, la jueza instructora María Servini documentó a 28 argentinos fusilados por el régimen (Irigaray). Entre ellos se encuentran los 197 de brigadistas argentinos que, durante la guerra civil, lucharon junto a la república (Clarín, "Guerra Civil’”). Avanzando el tiempo, la persecución a la 'subversión' de la última dictadura cívico-militar traspasaría las fronteras para llegar a España, aprovechando las renovadas relaciones con el país. Una de sus víctimas fue Noemí Gianetti, Madre de Plaza de Mayo que, en 1980, fue asesinada en Madrid mientras buscaba ayuda internacional para encontrar a su hija y yerno detenidos-desaparecidos (véanse los artículos de Albin).

La compleja situación de violencia y crisis económica del país rioplatense motivó que, volviendo a sus raíces, parte de la ciudadanía argentina emigrase a España. Los saldos migratorios son más elevados en el periodo 1975-1984, sólo superado por la crisis del corralito en 2000 (Actis y Esteban 211-212; Mira). Se confirma de esta manera el 'sistema migratorio' entre Argentina y España que fortaleció el entrecruzamiento de memorias transitadas por dos periodos dictatoriales. Una de las migrantes fue la propia Estela Martínez de Perón que, tras estar presa entre 1976 y 1981, volverá a Madrid, donde reside actualmente (Galiacho). Amparada por la justicia española ante las peticiones argentinas de extradición por diversos crímenes cometidos durante su gobierno, que España considera prescritos (La Nación, "Isabel Perón"). Si la memoria política se escribe sobre renglones amnéticos, primando los intereses de toda índole antes que los derechos humanos, la memoria democrática luchará por revertir esta tendencia desde una razón anamnética.

\section{Memoria democrática}

El concepto de memoria histórica es definido por Paloma Aguilar como "la 'memoria prestada' de acontecimientos del pasado que el sujeto no ha experimentado personalmente" (Aguilar 41). Cuando este pasado alude a la revisión de conflictos armados que desestabilizan o interrumpen una democracia, o a regímenes no democráticos que derrocan gobiernos legítimos, hablamos más específicamente de 'memoria democrática'. Este concepto nos obliga a repensar los antónimos dialécticos y decir con Yerushalmi 
(117): "Is it possible that the antonym of 'forgetting' is not 'remembering', but justice?". Podemos decir que la memoria es un elemento de la justicia, a través de la cual se conoce la verdad de los hechos, convirtiéndose en un deber y un derecho que trasciende lo individual para ser colectivo, y en esta instancia convertirse en un elemento político y reclamado desde una teoría crítica de los derechos humanos.

Este derecho a la memoria se concreta en el Informe Joinet de 1997, a través del derecho a la verdad, a la justicia, a la reparación y a la no repetición, en un modelo de justicia transicional anamnético centrado en las ofensas a las víctimas y en la lucha contra la impunidad e imprescriptibilidad de los crímenes de lesa humanidad que bajo el artículo 7 del Estatuto de la Corte Penal Internacional (1998) "supone un ataque generalizado o sistemático contra una población civil, y con conocimiento de dicho ataque". Esta tipificación ha sido aplicada tanto a los crímenes del franquismo como a los crímenes de la dictadura de las Juntas Militares. Un derecho que es un deber de memoria para los Estados que, según Mate significa hacer "presente el pasado ausente que es fundamentalmente el pasado de una injusticia” (Zamora y Mate 204).

\section{Justicia e impunidad en Argentina y España}

En Argentina, hay un intento del primer gobierno democrático, liderado por Raúl Alfonsín en 1983 de ocuparse del pasado a través de la creación de la Comisión Nacional sobre la Desaparición de Personas (CONADEP) (Decreto 187 de diciembre de 1983) y el Decreto 158/83 para procesar judicialmente a las Juntas militares. Este último y la aplicación de justicia sería finiquitado a través de la Ley 23.492 de Punto Final (1986) extinguiendo la acción penal, y la Ley 23.521 de Obediencia Debida (1987), mediante la que se absolvía a militares de rango intermedio e inferior de toda responsabilidad penal. Unas Leyes de Amnistía e impunidad que se completarían en el gobierno de Carlos Menem con una serie de indultos entre 1989 y 1990.

Ante esta situación, desde 1998 se crearon los 'juicios por la verdad', para esclarecer el paradero de las personas desaparecidas. Fue una propuesta de las organizaciones de derechos humanos y los familiares de las víctimas que, basándose en fallos de la Corte Interamericana de Derechos Humanos e informes de la Comisión Interamericana de Derechos Humanos sobre el derecho a la verdad, pidieron a los tribunales argentinos la reanudación de las investigaciones a fin de conocer la verdad, aun cuando el castigo no fuera posible (Méndez).

En 1998, los diputados argentinos Cafiero y Bravo proponen la derogación de la Ley de Punto Final y la Ley de Obediencia Debida, lográndose mediante la Ley 24.952 de 1998. En 2001, en plena crisis económica en Argentina, el presidente de la Rua (1999-2001) cursa el Decreto 1581 en 2001 que rechaza todos los pedidos de extradición contra los represores argentinos. Este decreto sería derogado por el presidente Kirchner mediante el Decreto 420 de 2003 de Cooperación Internacional en Materia Penal, que coincide con la petición del Juez Garzón de extradición de 46 argentinos implicados en la dictadura. Con la apertura de los juicios en Argentina, en 2003, los juzgados españoles pasaron a colaborar con los argentinos, como veremos seguidamente. 
Junto con esto, varios juzgados federales empiezan a declarar inconstitucionales las Leyes de Punto Final, Obediencia Debida y los indultos de Menem. En 2003, la Ley 25.779 declara estas leyes "insanablemente nulas". Este fue el precedente que permitió iniciar los juicios penales contra crímenes de la dictadura en Argentina. Algo que quedó confirmado en la declaración de inconstitucionalidad de las leyes de Punto Final y Obediencia Debida en el Caso Simón (2005) de la Corte Suprema de Justicia de la Nación, en base a que el alcance nacional de las leyes no estaba por encima del alcance internacional de la imprescriptibilidad de los crímenes de lesa humanidad.

De este modo comienzan los juicios contra crímenes de lesa humanidad cometidos durante la última dictadura en Argentina. Esto fue posible por el momento de oportunidad histórica que se estaba celebrando en Argentina en base a los siguientes factores: descapitalización de los actores represores (ejército) y los poderes fácticos (Iglesia católica), llaves internas de las leyes de impunidad que permitían su derogación, el avance jurídico de la apropiación de niños y niñas durante la dictadura, la lucha de movimientos de derechos humanos y memorialistas, la acción internacional de organismos como la Comisión Interamericana de Derechos Humanos o Amnistía Internacional, interpretación de las leyes nacionales centrada en la supremacía del derecho internacional y en el interés de las víctimas, o la acción política receptiva a las demandas sociales.

En España, no se daría ni tan siquiera una primera oportunidad a la verdad y a la justicia. En plena transición política, el gobierno de Adolfo Suárez decreta una primera amnistía parcial en 1976, y un año después llegaría la amnistía general. Estas leyes han sido usadas por diversos fallos de la Audiencia Nacional o el Tribunal Constitucional para negar la investigación de personas condenadas, asesinadas o desaparecidas durante la guerra civil y el franquismo (Escudero).

Tan sólo la Ley de Memoria Histórica de 2007 intenta recuperar parte de ese pasado, pero sin verdad, justicia y sin presupuesto desde 2013 (Público). Si la acción política iba de una visión atemperada de la memoria a la nada misma, la circunscripción jurídica de la Audiencia Nacional se vería interrumpida por sí misma. La insatisfacción ante la Ley de Memoria Histórica provocó que una reorganizada sociedad civil memorialista denunciase en sede jurídica la desaparición de sus familiares. Ante estas denuncias el juez Baltasar Garzón se consideró competente para investigar a los responsables de los hechos mediante el Auto de 16 de octubre de 2008, Diligencias Previas-Procedimiento Abreviado 399/2006 V, del Juzgado Central de Instrucción No 5 de la Audiencia Nacional. El Ministerio Fiscal se había manifestado meses antes no admitiendo a trámite las denuncias presentadas ya que los hechos no son constitutivos de crímenes de lesa humanidad o genocidio, que estaban bajo la Ley de Amnistía de 1977 y que la competencia en todo caso era del juez territorial del lugar donde los hechos hubieran ocurrido.

Garzón sería apartado y acusado por prevaricación. La Sentencia de la Sala de lo Penal del Tribunal Supremo, de 27 de febrero de 2012, absuelve a Baltasar Garzón del delito de prevaricación por este tema y declara la imposibilidad legal de investigar en los tribunales españoles los crímenes de la guerra civil y la dictadura franquista. Entre los fundamentos, el hecho de ser un proceso indagatorio y no penal, en analogía con los Juicios de la Verdad argentinos que escapa a las competencias del sistema penal español (Maculan). 
Estos impedimentos en España para investigar los crímenes del franquismo han sido severamente criticados por diversos órganos de tratados y mecanismos de derechos humanos de la ONU (Comité de Derechos Humanos de la ONU, Comité de la ONU contra la Tortura, Grupo de Trabajo sobre las Desapariciones Forzadas y Relator Especial sobre la promoción de la verdad, la justicia, la reparación y las garantías de no repetición). La respuesta del Estado español ante estos informes es coincidente con la jurídica, al ampararse en la Ley de Amnistía, la falta de ratificación de convenios internacionales en el momento del cometimiento de los hechos y el consenso de la transición: "la transición española constituye un caso único de reconciliación nacional sin justicia penal, por decisión deliberada y consensuada por la inmensa mayoría de las fuerzas políticas parlamentarias de evitar la justicia transicional. El equilibrio entre los distintos intereses, paz y democracia, justicia y reconciliación, se encontró en España a costa de renunciar a la justicia penal." (Informe del Relator Especial sobre la promoción de la verdad, la justicia, la reparación y las garantías de no repetición).

Una transición que ignoró en gran parte la lucha de los movimientos sociales durante el último franquismo (Sartorius). Una transición que no dialogó en horizontalidad con la izquierda política y pidió poner distancia respecto al sistema ilegítimamente derrocado, la II República, a cambio de renunciar presuntamente al franquismo, en el que hundió sus cimientos mediante pactos de 'consenso' que generaron una democracia de baja intensidad (Monedero 105-107). Esta otra cara estuvo llena de amenazas (no consensos), de miedos y presión (no libertad) y un pacto de silencio (no recuperación de las identidades oprimidas), del que surge la amnistía como una losa sobre la memoria, el olvido de las personas desaparecidas y la transmisión institucional del régimen anterior con la falsa imagen de haberlo derrotado: "la derrota del antifranquismo en la transición ha condicionado la pervivencia de vicios autoritarios en la realidad española” (Ruiz-Huerta 367).

\section{La justicia universal de España en Argentina}

Frente a la memoria política y oficial que mediante amnistías y amnesias pretenden establecer una razón amnética de sus violencias recientes, los movimientos memorialistas y la justicia defienden una razón anamnética capaz de recuperar y reivindicar la contramemoria de las víctimas y sus supervivientes. Esto se hace traspasando los límites territoriales gracias al principio de justicia universal, en base al deber de los Estados a investigar y a amparar jurídicamente a las víctimas. Jurídicamente, es un concepto basado en el derecho internacional que se establece en el Tribunal de Núremberg (1954-1946) y consagrado en los estatutos de los Tribunales Penales para la ex Yugoslavia (1993) y Ruanda (1994), así como en el Estatuto de Roma de la Corte Penal Internacional (1998).

Hay que destacar la incidencia política de organismos de derechos humanos frente a las Juntas Militares (Forni 556). Estos movimientos apoyaban a familiares de personas desaparecidas, que se organizaron ad hoc como Madres y Abuelas de Plaza de Mayo, apoyando recursos de habeas corpus y actuando de altavoz en el exterior o el CELS (Centro de Estudios Legales y Sociales) que desarrollarían una importante labor en el plano jurídico. Ante la impunidad nacional, estos movimientos se ampararían en el marco de la justicia universal para abrir procesos en el extranjero por ciudadanas y 
ciudadanos de otras nacionalidades asesinados y desaparecidos en Argentina durante la última dictadura.

En España, el proceso comenzó el 28 de marzo de 1996 mediante la Denuncia de la Asociación Progresista de Fiscales de España ante las personas desaparecidas en Argentina. En los fundamentos de derecho afirman que los crímenes tienen un carácter internacional e imprescriptible y que las leyes de Punto Final y Obediencia Debida no tienen validez en España en base al principio de soberanía nacional. La denuncia fue asignada al Juzgado de Instrucción número 5 de la Audiencia Nacional española con el magistrado Baltasar Garzón. Durante el mes de abril de 1996 se amplió con una acusación popular y se concretó con nombres de víctimas y victimarios. En el auto de conclusión de sumario en 2003, Garzón dicta auto de procesamiento por delitos de terrorismo y genocidio contra el capitán de la armada Adolfo Scilingo, el capitan de la armada Ricardo Miguel Carballo y 97 personas más implicadas en el centro clandestino de detención de la ESMA. Fue contra Scilingo el único juicio que prosperó en España, coincidiendo con la derogación de las leyes de impunidad en Argentina, lo que permitió seguir a la justicia argentina su propio rumbo (Gil).

Garzón pudo desarrollar el juicio ya que se acogió al principio de la justicia universal, consagrado en el artículo 23 de la Ley Orgánica 1/2009, de 3 de noviembre, de reforma de la legislación procesal, que amplía las competencias de la jurisdicción española al incorporar tipos de delitos que no estaban incluidos y cuya persecución viene amparada en los convenios y costumbre del Derecho Internacional, como son los de lesa humanidad, genocidio y crímenes de guerra cometidos por españoles o extranjeros fuera del territorio nacional. Esta reforma vuelve a ser reformada mediante la Ley Orgánica 1/2014, de 13 de marzo, relativa a la justicia universal, limitando la acción penal española en el exterior cuando víctimas o victimarios sean de nacionalidad española.

\section{La justicia universal de Argentina en España}

Si la impunidad legal no fue impedimento en Argentina para revisar su pasado violento, en España no hay voluntad jurídica y política de enfrentarse a los crímenes del franquismo. Pese a ello, la acción solidaria de los organismos de derechos humanos creados ad hoc durante la última dictadura argentina y la cantidad de españolas/es y descendientes, en parte exiliadas y exiliados, establecieron puentes con asociaciones memorialistas españolas.

Durante los años 1990 y 2000 se había reorganizado un importante movimiento memorialista con motivo de los aniversarios de la II República y la Guerra Civil, reclamando el derecho a la memoria en materia de justicia o de exhumaciones. Desde 2000 es la Asociación para la Recuperación de la Memoria Histórica (ARMH) o la Federación Estatal de Foros por la Memoria creada en 2004. El momento de estabilidad democrática, los aniversarios de la guerra civil y la capacidad de las víctimas para poder hablar sin miedo hace que se cree una sociedad civil organizada y reactiva que hace incidencia en grupos políticos tradicionalmente opuestos y represaliados por el franquismo como el PSOE o Izquierda Unida, de modo que, bajo el desarrollo normativo de Naciones Unidas sobre la impunidad y la memoria se retome el tema en España y se cuestione la Ley de Amnistía de 1977. 
El precedente de justicia universal de Garzón y los lazos migrantes entre España y Argentina hizo que, ante el desamparo político y jurídico nacional y el incumplimiento de las obligaciones internacionales, los organismos recurran a la justicia universal en Argentina. En este país, el principio de justicia universal está consagrado jurídicamente en el artículo 18 de su Constitución. Y más específicamente en el artículo 5 de la Ley 26.200 de 13 de noviembre de 2006. A esto hay que sumar el Tratado de Extradición y Asistencia Judicial en Materia Penal entre La República Argentina y el Reino de España (1987) y la Resolución AG-2010-RES-10 de Interpol sobre cooperación en materia de crímenes contra la humanidad, genocidio y crímenes de guerra.

En este marco legal el 14 de abril de 2010 se interpuso una querella en el Juzgado Nacional en lo Criminal y Correccional Federal $N^{o}$ 1, de Buenos Aires, a cargo de la jueza María Servini, con el objetivo de investigar los crímenes cometidos por integrantes de la dictadura franquista, identificar y sancionar penalmente a los responsables. La Querella 4591/2010, nominada "N.N. por genocidio y/o crímenes de lesa humanidad cometidos en España por la dictadura franquista entre el 17 de julio de 1936, comienzo del golpe cívico militar, y el 15 de junio de 1977, fecha de celebración de las primeras elecciones democráticas", fue presentada por familiares de personas asesinadas y desaparecidas durante la dictadura y diversas asociaciones españolas y argentinas, representadas por los abogados argentinos Carlos Slepoy (fallecido en 2017), Ana Messuti y Máximo Castex bajo el paraguas de la Coordinadora estatal de apoyo a la Querella Argentina contra crímenes del franquismo (CEAQUA).

En realidad, la 'querella argentina' agrupa a más de 300 querellas y más de un centenar de denuncias presentadas ante el Consulado de Argentina en Madrid, un proceso que sigue vigente. Las personas querellantes o denunciantes pueden ser desde las víctimas directas hasta sus descendientes en un gran cruce intergeneracional de memoria y postmemoria, de lo vivido, recordado y relatado y considerando que la culpa no se transmite, pero sí la victimización. La cooperación entre el juzgado argentino y los españoles ha estado llena de desencuentros y tensiones. Frente a los argumentos de justicia universal e imprescriptibilidad estaban los de amnistía y prescriptibilidad.

Ante la falta de cooperación de los juzgados españoles, en marzo 2012, Servini acuerda tomar declaraciones durante los meses de junio-julio en Madrid, visita que finalmente no se produjo, de modo que las declaraciones a las víctimas se tuvieron que programar por videoconferencia en el Consulado de Argentina en Madrid en mayo de 2013, hecho que fue suspendido ante el malestar expresado mediante nota verbal por el Ministerio de Asuntos Exteriores y Cooperación. Tras esto, se acordó un pedido internacional de captura que impidiera a los acusados salir del país (Chientaroli). Servini tras un nuevo exhorto finalmente viajó a España en mayo de 2014 con el objetivo de reunirse con instituciones del Estado, recabar información en archivos y tomar declaración a víctimas y querellantes en tribunales territoriales (Guenaga; Baquero y Guenaga).

En 2015 CEAQUA pretende implicar más a la política en la querella, buscando apoyos de partidos políticos y de ayuntamientos para que se querellen en nombre de su ciudadanía, creándose la Red de Ciudades por la Justicia y la Memoria. Ya se han querellado los ayuntamientos de Pamplona, Vitoria y Tarragona; se han aprobado la presentación de querellas en Barcelona, Zaragoza, Coruña, Cádiz, Leganés, Miranda del Ebro, Aranda del Duero, Puerto Real, Lagrea, Rivas, Guernica, Durango u Ochandiano. Se han solicitado Valencia, Bilbao, Santander y Madrid. 
En marzo de 2016, Servini pide interrogar en España a 19 imputados entre los que se encuentran los exministros franquistas y expolícias torturadores, petición que sería derivada a los juzgados territoriales (Baquero, "Justicia"; Agencia EFE). Pero, en octubre de ese año, Consuelo Madrigal como Fiscal General del Estado manda una circular a los juzgados territoriales pidiendo suspender la declaración que querellantes y víctimas estaban prestando desde 2015 así como cualquier solicitud de cooperación formulada por la justicia argentina, alegando que los hechos investigados están cubiertos por la Ley de Amnistía de 1977, que no se puede cuestionar la transición y que ya existe la Ley de Memoria Histórica, con argumentos más políticos que jurídicos (Águeda y Precedo).

La querella también está siendo importante por que incorpora por primera vez elementos de género. Así, en marzo de 2016, la organización Women’s Link Wordwide presenta ante la jueza Servini una querella para solicitar la investigación de los crímenes de género cometidos durante el franquismo (Women's Link Worldwide). Finalmente debemos destacar un gran logro de los múltiples exhortos de Servini a juzgados españoles. Nos referimos a la búsqueda y exhumación de Timoteo Mendieta, reclamado por su hija Ascensión. Mendieta fue fusilado en 1939 en el pueblo guadalajareño de Sacedón por su filiación sindical en UGT. Finalmente, el juzgado de instrucción $\mathrm{n}^{\mathrm{o}} 1$ de Guadalajara ordenó la exhumación de dos fosas comunes en el cementerio de la ciudad, y tras identificar su cuerpo en 2017 pudo ser enterrado (Bachiller y Sánchez).

En este punto se encuentra la querella argentina que ha conseguido rasgar el duro telón de impunidad en España y sigue buscando nuevos cauces a base de una imaginación política radical, con el apoyo de Naciones Unidas y despertando susceptibilidades en una sociedad que se mueve entre la amnesia y la fragmentación que la Transición pretendió ocultar.

\section{Conclusiones}

Comparar crea incertidumbre y la incertidumbre conocimiento. No tenemos por qué enfrentarnos a nuestra propia esfinge en soledad. Cuando comparamos, miramos y este ejercicio abre un abismo dialéctico entre aquello que vemos y lo que nos mira: "para saber, hay pues que colocarse en dos espacios y en dos temporalidades a la vez. Hay que implicarse.” (Didi-Huberman 17) Es la dicotomía entre 'uno' y 'otro'. Etimológicamente 'otro' viene del latín alter, y este del indoeuropeo 'al-' (otro) y '-ter' (sufijo que marca contraste u oposición). En realidad, el 'uno' y el 'otro' conforman el 'nosotros', donde está la dimensión ética y solidaria de la comparación. Donde nos implicamos.

Efectivamente a lo largo de este artículo, nos hemos colocado en dos espacios (España y Argentina) y dos temporalidades (franquismo y dictadura de las Juntas Militares), con el objeto de implicarnos en ir más allá de nuestra memoria e historia, para retomarla desde una razón anamnética centrada en la dignidad de las víctimas. El ejemplo de Argentina, centrado en el derecho a la memoria toca a la puerta del deber de olvido español para afirmar que no hay fronteras en la justicia universal. Y más allá, que no hay excusas ante una historia compartida desde la colonialidad, la hispanidad, 
las migraciones y los exilios como torrentes bajo las relaciones políticas de ambos países. Una memoria, en definitiva, que se reclama mutuamente como propia, en una distancia, la de los antónimos dialécticos que parece no tener fin.

Pero la comparación no es sólo 'entre' sino 'desde'. Es decir, desde qué materias o documentos comparamos. Si no tiene mucho sentido el análisis cerrado de una memoria sin ver las fluctuaciones 'entre' otras memorias, ¿qué sentido puede tener comparar sólo 'desde' una materia, 'desde' un tipo de documento? Recordemos un momento a Walter Benjamin: "jamás se da un documento de cultura sin que lo sea a la vez de barbarie" (Benjamin 18). Con esto nos advierte que las fuentes, como la jurídica que hemos usado están insertas en un contexto específico y que toda interpretación aislada de la misma supone una alienación (Balkin y Levinson). Por esto se deben leer desde la interdisciplinariedad de las humanidades y desde la razón de las víctimas. Es esta comparativa la que delimita la consecución del derecho a la memoria. La que va de una interpretación abstracta de la ley a una humana.

El pasado compartido entre España y Argentina y un presente que se enfrenta a unos hechos violentos y traumáticos difiere en los modos con los que se lidian. Cada país rescata y archiva de manera diferente los mismos hechos de su memoria colectiva constreñida en una memoria oficial: memoria y olvido, prescripción e imprescriptibilidad, retroactibilidad e irretroactibilidad, consenso y disenso, impunidad y dignidad de las víctimas, razón amnética y razón anamnética, derecho a la memoria y deber de olvido. Demostrando así que las llaves de nuestra propia identidad pueden encontrarse más allá del océano... en una relación fluctuante y coincidente al afirmar que memoria y justicia son sinónimos.

\section{Bibliografía}

ABC. "Defensa envía a Garzón una lista de diez militares que visitaron Argentina durante la represión.” $A B C$ (5 mayo 1998). Web. 2 julio 2918.

Actis, Walter y Fernando O. Esteban. “Argentinos hacia España ('sudacas' en tierras 'gallegas'): el estado de la cuestión." Sur-Norte. Estudios sobre la migración reciente de argentinos. Ed. Susana Novik. Buenos Aires: Catálogos Editora/Universidad de Buenos Aires, 2007. 205-258.

Acusación popular ante la denuncia por las personas desaparecidas en Argentina. Web. 2 julio 2018.

Agencia EFE: "La Fiscalía torpedea las declaraciones de cargos franquistas y víctimas ordenadas por Argentina.” El Diario (5 octubre 2016). Web. 2 julio 2018.

Águeda, Pedro y José Precedo. "La Fiscalía advierte a la jueza Servini de que no puede cuestionar la transición española." El Diario (6 octubre 2016). Web. 2 julio 2018.

Aguilar, Paloma. Memoria y olvido de la Guerra Civil Española. Madrid: Alianza Editorial, 1996. 
Albin, Danilo. "El Gobierno justifica el apoyo español a la dictadura de Videla." Diario Público (3 marzo 2015). Web. 2 julio 2018.

Albin, Danilo. "España financió a la dictadura de Videla." Diario Público (10 octubre 2014). Web. 2 julio 2018.

Albin, Danilo. "La dictadura de Videla y España intercambiaron apoyos, medallas y regalos." Diario Público (21 octubre 2014). Web. 2 julio 2018.

Albin, Danilo. "Militares argentinos mataron hace 30 años en Madrid a Noemí Gianetti, una de las madres de la plaza de mayo." Interviú (14 diciembre 2009). Web. 2 julio 2018.

Albin, Danilo. "Videla envió los archivos de la represión, con las listas de desaparecidos, a España, Suiza e Israel.” Diario Público (12 abril 2015). Web. 2 julio 2018.

Algañaraz, Juan Carlos. "Todos los caminos llevaban a Puerta de Hierro." Clarín 1 (2004). Web. 2 julio 2018.

Alted Vigil, Alicia. La voz de los vencidos: El exilio republicano de 1939. Madrid: Aguilar, 2005.

Amorós, Celia. Vetas de ilustración. Reflexiones sobre feminismo e Islam. Madrid: Cátedra, 2009.

Audiencia Nacional. Caso Scilingo. Web. 2 julio 2018.

Audiencia Nacional. Diligencias previas proceso abreviado 399/2006 V. Web. 2 julio 2018.

Audiencia Nacional. Fallo querella manos Limpias. Web. 2 julio 2018.

Aznar, Yayo y Diana B. Wechsler. "Introducción. Una historia compartida." La memoria compartida: España y la Argentina en la construcción de un imaginario cultural: 18981950. Ed. Yayo Aznar y Diana B. Wechsler. Buenos Aires: Paidós, 2005. 15-27.

Bachiller, Carmen y Teresa Sánchez Garzón. "Identificado el cuerpo de Timoteo Mendieta en el cementerio de Guadalajara.” El Diario (9 junio 2017). Web. 2 julio 2018.

Baquero, Juan Miguel y Aitor Guenaga. "Siete historias de la represión franquista que conocerá la jueza Servini.” El Diario (19 mayo 2014).

Baquero, Juan Miguel. "El Gobierno tramita por fin la petición argentina de interrogar a Martín Villa y a otros 18 cargos franquistas." El Diario (26 septiembre 2016).

Baquero, Juan Miguel. "La justicia argentina pide interrogar en España a 19 imputados por crímenes franquistas.” El Diario (22 marzo 2016). Web. 2 julio 2018.

Balkin, Jack M. y Stanford Levinson. "El derecho y las humanidades: una relación incómoda." Revista Jurídica de la Universidad de Palermo 9.1 (2008): 197-228.

Benjamin, Walter. Discursos interrumpidos, I. Madrid: Taurus, 1973.

Bhabha, Homi K. "On Writing Rights." Globalizing Rights: The Oxford Amnesty Lectures. Ed. Matthew J. Gibney. Oxford: Oxford University Press, 2003. 162-183.

Bins, Niall (Ed.). Argentina y la guerra civil española. La voz de los intelectuales. Madrid: Calambur, 2012. 
Calvo Salgado, Luís M. at al. (Ed.). Historia del Instituto Español de Emigración. La politica migratoria exterior de España y el IEE del Franquismo a la Transición. Madrid: Ministerio de Trabajo e Inmigración, 2009.

Carnagui, Juan Luis. "La ley de represión de las actividades comunistas de 1936: miradas y discursos sobre un mismo actor." Revista Escuela de Historia 6 (2007). Web. 2 julio 2018.

Castilla del Pino, Carlos (2006). "La forma moral de la memoria. A manera de prólogo.” El derecho a la memoria. Ed. Felipe Gómez Isa. Guipuzkoa: Alberdania, 2006. $15-22$.

CEAQUA. Red de Ciudades por la Justicia y la Memoria. Web. 2 julio 2018.

Chientaroli, Natalia. "El Gobierno pone trabas a un juicio internacional contra crímenes franquistas." El Diario (25 mayo 2015). Web. 2 julio 2018.

Clarín. "Guerra Civil española: los argentinos que fueron a pelear contra Franco." Clarin (4 junio 2006). Web. 2 julio 2018.

Clarín. "Se ofició en la Catedral un funeral por Franco." Clarin (28 noviembre 1975). Web. 2 julio 2018.

Cobo, Rosa. "El género en las ciencias sociales.” Revista de Trabajo Social 18 (2005): 249_ 258.

Comité de Derechos Humanos de la ONU. Examen de los informes presentados por los Estados partes con arreglo al artículo 40 del Pacto. Observaciones Finales. 2009. Web. 2 julio 2018.

Comité de Derechos Humanos de la ONU. Observaciones finales sobre el sexto informe periódico de España. 2015. Web. 2 julio 2018.

Comité de la ONU contra la Tortura. Examen de los informes presentados por los Estados partes en virtud del artículo 19 de la Convención. Observaciones finales del Comité contra la Tortura. España. 2009. Web. 2 julio 2018.

Comité de la ONU contra la Tortura. Observaciones finales sobre el sexto informe periódico de España. 2015. Web. 2 julio 2018.

Corte Suprema de Justicia. Caso Simón. Web. 2 julio 2018.

Coser, Lewis A. "Introduction. Maurice Halbwachs 1877-1945.” Maurice Halbwachs. On collective memory. Chicago \& London: University of Chicago Press, 1992. 1-34.

Decreto 158 de 1983 sobre el proceso a las Juntas Militares. Web. 2 julio 2018.

Decreto 1581 en 2001 de rechazo de extradición contra los represores argentinos. Web. 2 julio 2018.

Decreto 187 de 1983 sobre la Comisión Nacional sobre la Desaparición de Personas. Web. 2 julio 2018.

Decreto 261 de 1975 que autoriza el operativo independencia. Web. 2 julio 2018.

Delgado Gómez-Escalonilla, Lorenzo. Diplomacia franquista y política cultural hacia Iberoamérica, 1939-1953. Madrid: CSIC, 1988. 
Denuncia de la Asociación Progresista de Fiscales de España ante las personas desaparecidas en Argentina. Web. 2 julio 2018.

Desestimación de la Querella 4591/2010. Web. 2 julio 2018.

Devoto, Fernando. Historia de la inmigración en la Argentina. Buenos Aires: Editorial Sudamericana, 2002.

Didi-Huberman, Georges. Lo que vemos, lo que nos mira. Buenos Aires: Ediciones Manantial, 1997.

Di Febo, Giuliana. Ritos de guerra y de victoria en la España franquista. Valencia: Universitat de València, 2012.

El Diario. "Se constituye la plataforma de apoyo a la querella argentina contra los crímenes del franquismo." El Diario (9 noviembre 2015). Web. 2 julio 2018.

El País. "Hablan los primeros liberados por la gestión del Rey." El País (1 julio 1979). Web. 2 julio 2018.

Escudero Alday, Rafael. “Ambito Jurídico. Asociación para la Recuperación de la Memoria Histórica.” Web. 2 julio 2018.

Figallo, Beatriz. Argentina ante la guerra civil española. Rosario: Instituto de Historia de la Facultad de Derecho y Ciencias Sociales de la UCA, 1996.

Forni, Floreal. "Derechos Humanos y trabajo de base: la reproducción de una línea en el catolicismo argentino." 500 años de cristianismo en Argentina. M. Cristina Liboreiro et al. Buenos Aires: Cheila-Nueva Tierra, 1992. 513-524.

Foucault, Michel. "Film and Popular Memory." Foucault Live (Interviews, 1961-1984). Ed. Sylvère Lotringer. New York: Semi-text(e), 1989.

Foucault, Michel. Language, Counter-Memory, Practice. Selected Essays and Interviews. Ithaca: Cornell University Press, 1977.

Foucault, Michel. Power/Knowledge. Selected Interviews and Other Writings 1972-1977. New York: Pantheon Books, 1980.

Foucault, Michel. Society Must Be Defended. New York: Picador, 2003.

Galiacho, Juan Luis. "María Estela de Perón, enterrada en vida en Madrid: la argentina a la que no verá Macri.” El Español (22 febrero 2017). Web. 2 julio 2018.

Gil Gil, Alicia. "La sentencia de la Audiencia Nacional en el Caso Scilingo." Revista Electrónica de Ciencia Penal y Criminológica 7 (2005). Web. 2 julio 2018.

Gil Pecharromán, Julio. Con permiso de la autoridad. La España de Franco (1939-1975). Madrid: Temas de Hoy, 2008.

Guenaga, Aitor "La jueza Servini viaja a España para investigar los crímenes del franquismo." El Diario (13 mayo 2014). Web. 2 julio 2018.

Halbwachs, Maurice. La memoria colectiva. Zaragoza: Prensas Universitarias de Zaragoza, 2004.

Hirsch, Marianne. Family frames. Photography, narrative and postmemory. London: Harvard University Press, 2002. 
Hutton, Patrick H. History as an art of memory. Hanover and London: University Press of New England, 1993.

Indultos de Menem de 1989 y 1990. Web. 2 julio 2018.

Informe del Grupo de Trabajo sobre las Desapariciones Forzadas o Involuntarias. 2012. Web. 2 julio 2018.

Informe del Grupo de Trabajo sobre las Desapariciones Forzadas o Involuntarias. Misión a España. 2014. Web. 2 julio 2018.

Informe del Relator Especial sobre la promoción de la verdad, la justicia, la reparación y las garantías de no repetición, Pablo de Greiff. Misión a España. 2014. Web. 2 julio 2018.

Informe del Relator Especial sobre la promoción de la verdad, la justicia, la reparación y las garantías de no repetición, Pablo de Greiff. Misión a España: Comentarios del Estado al informe del Relator Especial. 2014. Web. 2 julio 2018.

INTERPOL. Co-operation with new requests concerning genocide, crimes against bumanity and war crimes. Web. 2 julio 2018.

Irigaray, Juan Ignacio. “El franquismo fusiló a 28 argentinos.” El Mundo (1 junio 2014). Web. 2 julio 2018.

Klein, Kerwin L. "On the Emergence of Memory in Historical Discourse." Representations 69 (2000): 127-150.

La cuestión de la impunidad de los autores de violaciones de los derechos bumanos (civiles y políticos). Informe final elaborado y revisado por M. Joinet. Web. 2 julio 2018.

La Nación. “Oficiales españoles, testigos de la represión argentina." La Nación (4 abril 1998). Web. 2 julio 2018.

La Nación. "Rechazó la justicia española la extradición de Isabel Perón.” La Nación (18 abril 2008). Web. 2 julio 2018.

LaCapra, Dominick. Historia en tránsito. Experiencia, identidad, teoría crítica. México/Buenos Aires: Fondo de Cultura Económica, 2006.

Lavabre, Marie-Claire (2006). "Sociología de la memoria y acontecimientos traumáticos.” Guerra civil. Mito y memoria. Ed. Julio Aróstegui y François Godicheau. Madrid: Marcial Pons, 2006. 31-56.

Ley 20.840 de Seguridad Nacional de 1974. Web. 2 julio 2018.

Ley 23.492 de 1986 de Punto Final. Web. 28 agosto 2017. Web. 2 julio 2018.

Ley 23.521 de 1987 de Obediencia Debida. Web. 2 julio 2018.

Ley 24.952 de 1998. Web. 2 julio 2018.

Ley 25.779 de 2003 declarando las leyes de impunidad "insanablemente nulas". Web. 2 julio 2018.

Ley 46/1977 de 15 de octubre sobre amnistía general. Web. 2 julio 2018. 
Ley 52/2007, de 26 de diciembre, por la que se reconocen y amplian derechos y se establecen medidas en favor de quienes padecieron persecución o violencia durante la guerra civily la dictadura. Web. 28 agosto 2017.

Ley Orgánica 1/ 2009, de 3 de noviembre, de reforma de la legislación procesal. Web. 2 julio 2018.

Ley Orgánica 1/2014, de 13 de marzo, relativa a la justicia universal. Web. 2 julio 2018.

Lozano Escribano, Tomás. "Hacia la supranacionalidad iberoamericana: la doble nacionalidad entre España y los países de la Comunidad Iberoamericana." Cuadernos de estrategia 86 (1996): 247-268.

Maculan, Elena. "Límites a la expansión de la persecución por crímenes internacionales y al papel del juez-historiador: la aportación de la STS 101/2012.” Revista de derecho penal y criminología 8 (2012): 497-518.

Maeztu, Ramiro: Defensa de la hispanidad. Madrid: Rialp, 1995.

Memoria del Ministerio de Relaciones Exteriores y Culto, 1948/1949.

Méndez, Juan E. "El derecho humano a la verdad. Lecciones de las experiencias latinoamericanas de relato de la verdad." Historizar el pasado vivo en América Latina. Ed. Anne Pérotin-Dumon. Santiago de Chile: Universidad Alberto Hurtado, 2007. Web. 2 julio 2018.

Metz, Johann Baptist. Por una cultura de la memoria. Barcelona: Anthropos, 1999.

Ministerio de Asuntos Exteriores (MAE). Informe oficial sobre los desaparecidos españoles en argentina. Realizado por el Ministerio de asuntos exteriores de España en respuesta al pedido de la diputada María Ángeles Maestro Martín. Web. 2 julio 2018.

Mira Delli-Zotti, Guillermo. “Argentinos hacia España: del exilio al éxodo.” Minorías y migraciones en la historia. XV Jornadas de Estudios Históricos organizadas por el Departamento de Historia Medieval, Moderna y Contemporánea. Ed. Ángel Vaca Lorenzo. Salamanca: Ediciones Universidad de Salamanca, 2004. 121-150.

Monedero, Juan Carlos. La Transición contada a nuestros padres. Nocturno de la democracia española. Madrid: Los Libros de la Catarata, 2011.

Muchnik, Daniel. Gallo Rojo Gallo Negro. Los intereses en juego en la guerra civil española. Buenos Aires: Grupo Editorial Norma, 2004.

Nilson, Cezar Mariano. Operación Cóndor. Terrorismo de Estado en el Cono Sur. Buenos Aires: Lholé-Lumen, 1998.

Obregón, Martín. Entre la cruz y la espada. La Iglesia católica durante los primeros años del Proceso. Bernal: Universidad Nacional de Quilmes, 2005.

Olick, Jeffrey K. y Joyce Robbins. "Social memory studies: from 'collective memory' to the historical sociology of mnemonic practices." Annual Review of Sociology 24 (1998): 105-140.

Palazón Ferrando, Salvador. Capital bumano español y desarrollo latinoamericano. Evolución, causas y características del flujo migratorio. Alicante: Institut de Cultura Juan Gil-Albert, 1995. 
Payne, Stanley G. "Los Estados Unidos y España: Percepciones, imágenes e intereses." Cuadernos de Historia Contemporánea 25 (2003): 155-167.

Pelta, Raquel: "Eva Perón, icono de la hispanidad." La memoria compartida: España y la Argentina en la construcción de un imaginario cultural: 1898-1950. Ed. Yayo Aznar y Diana B. Wechsler. Buenos Aires: Paidós, 2005. 165-188.

Pérez Leira, Luis. Desaparecidos españoles en la Argentina. Vigo: Grupo de Comunicación de Galicia en el Mundo, 2010.

Público. "El Gobierno elimina en 2013 el presupuesto para memoria histórica." Diario Público (29 septiembre 2012). Web. 2 julio 2018.

Querella 4591/2010. Web. 2 julio 2018.

Quijada, Mónica. Aires de República, Aires de cruzada. La guerra civil española en la Argentina. Barcelona: Sendai, 1991.

Real Decreto-ley 10/1976, de 10 de julio. Web. 2 julio 2018.

Rein, Raanan. La salvación de una dictadura. Alianza Franco-Perón, 1946-1955. Madrid: CSIC, 1995.

República Argentina. Memoria del Ministerio de Relaciones Exteriores y Culto, 1946-1947.

Resolución 39(I), la ONU de 1946. Web. 2 julio 2018.

Resolución de la Cámara Criminal y Correccional Federal ordena proseguir el proceso por delitos de genocidio y lesa humanidad impunes en España. Web. 2 julio 2018.

Robin, Marie-Monique. Escadrons de la mort, l'école française. París: La Découverte, 2004.

Ruiz-Huerta Carbonell, Alejandro. Los ángulos ciegos: una perspectiva crítica de la transición española, 1976-1979. Madrid, Biblioteca Nueva, 2009.

RUVTE. Estadísticas del Registro Unificado de Victimas del Terrorismo de Estado. Web. 2 julio 2018.

Said, Edward W. "Orientalism Reconsidered." Literature, Politics and Theory: Papers From the Essex Conference, 1976-1984. Eds. Francis Barker et al. London: Methuen, 1986. 210-229.

Sánchez Alonso, Blanca. "La emigración española a la Argentina." Españoles hacia América. La emigración en masa, 1880-1930. Ed. Nicolás Sánchez-Albornoz. Madrid: Alianza Editorial, 1995. 205-234.

Sartorius, Nicolás y Alberto Sabio. El final de la dictadura. La conquista de la democracia en España. Noviembre de 1975-junio de 1977. Madrid: Temas de Hoy, 2007.

Schwarzstein, Dora: "La llegada de los republicanos españoles a la Argentina." Estudios Migratorios Latinoamericanos 37 (1997): 423-447.

Schwarzstein, Dora: Entre Franco y Perón. Memoria e identidad del exilio republicano español en Argentina. Barcelona: Crítica, 2001.

Senado de España. Dictamen de la Comisión Especial de Investigación sobre Desaparición de Súbditos Españoles en Países de América. 1983. Web. 2 julio 2018. 
Senkman, Leonardo: "La política migratoria argentina durante la década de los 30. La selección étnica." Primeras Jornadas Nacionales de Estudios sobre Inmigración Argentina. Buenos Aires: Ministerio de Educación e Justicia, Secretaría de Cultura, 1985. 599_ 623.

Slatman, Melisa. "El Cono Sur de las dictaduras, los eslabonamientos nacionales en el interior de la Operación Cóndor y las particularidades del caso argentino." Represión estataly violencia paraestatal en la historia reciente argentina. Nuevos abordajes a 40 años del golpe de Estado. Ed. Gabriela Águila, Santiago Garaño y Pablo Scatizza. La Plata: Facultad de Humanidades y Ciencias de la Educación de la Universidad Nacional de La Plata, 2016. 451-474.

Tapia Valdés, Jorge A. El terrorismo de Estado. La Doctrina de la Seguridad Nacional en el Cono Sur. México D.F.: Editorial Nueva Imagen, 1980.

Tratado de extradición y asistencia judicial en materia penal entre la República Argentina y el Reino de España. Web. 2 julio 2018.

Trifone, Víctor y Gustavo Svarzman. La repercusión de la guerra civil en la Argentina (19361939). Buenos Aires: Centro editor de América Latina, 1993.

Verbitsky, Horacio. Vigilia de armas, t. 3. Del Cordobazo de 1969 al 23 de marzo de 1976. Buenos Aires: Sudamericana, 2009.

Women's Link Worldwide. "Las víctimas ‘olvidadas' de Franco: violencia sexual, tortura y humillación contra las mujeres.” Web. 2 julio 2018.

Yáñez Gallardo, César Roberto. “Argentina como país de destino. La emigración española entre 1860-1930.” Estudios Migratorios Latinoamericanos 13 (1989): 467-498.

Yerushalmi, Yosef Hayim. Zakhor. Jewish History and Jewish Memory. Washington: University of Washington Press, 1984.

Zamora, José Antonio y Reyes Mate (Ed.). Justicia y memoria. Hacia una teoría de la justicia anamnética. Barcelona: Anthropos, 2011. 